\title{
EVOLUINDO DA CADEIA DE VALOR PARA CADEIA DE SUPRIMENTOS
}

\section{EVOLVING FROM VALUE CHAIN TO SUPPLY CHAIN}

\author{
Cícero Marciano da Silva Santos* cícero marciano@yahoo.com.br \\ Maria Silene Alexandre Leite* leite@ct.ufpb.com.br \\ André Duarte Lucena* anduluc@hotmail.com \\ Tarcísio Ferreira Grilo Júnior* tarcisio jr@hotmail.com \\ * Universidade Federal de Pernambuco
}

\begin{abstract}
Resumo: Com a tendência das empresas concentrarem-se nas suas competências essenciais (core competences) e transferir a terceiros as demais atividades que antes eram executadas internamente em estruturas mais verticalizadas, a cadeia de valor das empresas tendem a assumir configurações estendidas e aumentar o número de empresas envolvidas na maioria das cadeias de suprimentos. Assim, o objetivo deste artigo é mostrar como a cadeia de valor pode contribuir para a compreensão da formação da cadeia de suprimentos de uma empresa. Para este fim foi realizado um estudo em uma empresa do setor de comunicação e mídia, uma empresa do setor gráfico e outra do setor governamental. Ao final da pesquisa foi possível construir a cadeia de suprimentos da empresa focal a partir da análise de sua cadeia de valor, bem como do seu cliente e fornecedor mais relevante.
\end{abstract}

Palavras Chaves: Cadeia de valor do produto. Cadeia de valor estendida. Cadeia de suprimentos.

Abstract: With the fact of the enterprises' tendency concentrated themselves in its core competences and to transfer via third party processing activities that before were executed internally, in more vertical structures, the enterprises value chain tend to assume spread out configurations and to increase the number of enterprises wrapped in majority supplies chains. So, the objective of this paper is show like the value chain can contribute to understand formation enterprises supplies chain. For this aim a study was carried out in an enterprise of the communication and media sector, an enterprise of the printing sector and other of the government sector. To the end of the research it was possible to build the focus enterprises supplies chain, from its value chain analyses and its supplier and customer more relevant.

Key-Words: Product value chain. Extend value chain. Supply chain.

\section{INTRODUÇÃO}

Num passado recente, o modelo adotado pelas organizações, principalmente por grandes empresas, se constituía de estruturas altamente verticalizadas, em que a maior parte das operações necessárias à produção e disponibilização de produtos aos clientes finais era executada por uma única empresa. Nessa configuração, as 
cadeias de suprimentos eram pouco complexas, face ao pequeno número de participantes (LEITE, 2004; GASPARETTO, 2003).

Dessa forma, nesse ambiente pouco complexo Porter (1989, p. 33) argumenta que "toda empresa é uma reunião de atividades que são executadas para projetar, produzir, comercializar, entregar e sustentar seu produto. Todas estas atividades podem ser representadas, fazendo-se uso de uma cadeia de valor."

Nota-se que nas últimas décadas, a complexidade de funcionamento das organizações vem aumentando e os sistemas produtivos, que antes operavam verticalmente nas empresas, apresentam uma maior tendência em desverticalizar seu processo produtivo, com isso, a terceirização nas cadeias produtivas provocada por essa desverticalização, tende a quebrar as barreiras das organizações e desenvolver cadeias de valor estendidas. As empresas passam então, nesse ambiente, a executar apenas parte das operações necessárias para disponibilizar determinado produto ao cliente final.

Com a terceirização das atividades de valor é possível estender a cadeia de valor além dos limites da empresa. Dessa forma, o conceito de cadeia de valor definido por Porter (1989) é questionado em função da terceirização e expansão geográfica dos processos produtivos (OHMAE, 1998; KAPLINSK e MORRIS 2000; KAPLINSK e READMAN, 2001; NOVAES, 2001; CHIAVENATO e SAPIRO, 2003; PIRES, 2004; CHRISTOPHER, 2007 e FARIAS; 2009).

Dessa forma, as atividades de valor do produto são compartilhadas por diversas empresas onde cada uma delas participa do processo de criação de valor, ou seja, a cadeia de valor se expande formando a cadeia de suprimentos. Percebem-se nesse momento três elementos: cadeia de valor do produto, cadeia de valor da empresa focal e cadeia de suprimentos.

Sendo assim, o objetivo deste artigo é mostrar como a cadeia de valor pode contribuir para a compreensão da formação da cadeia de suprimentos, a partir do estudo e mapeamento da cadeia de valor do produto, empresa focal e de seu fornecedor e cliente mais relevante. 


\section{ESTRUTURA TEÓRICA}

Para um melhor entendimento sobre o tema abordado, apresenta-se neste item uma breve revisão bibliográfica sobre: Cadeia de valor e Cadeia de Suprimentos.

\subsection{Cadeia de Valor e Cadeia de Suprimentos}

Segundo Porter (1989) as atividades são os pilares da construção de vantagens competitivas, sendo consumidoras de recursos, por um lado, e criadoras de valor, por outro. Já para Brimson (1996), são as atividades que convertem recursos em produtos, então o foco nas atividades permite entender o modo como uma empresa emprega seu tempo e recursos para alcançar os objetivos empresariais.

Numa visão mais abrangente Novaes (2001, p. 185) argumenta que "o valor de um produto é composto pela margem e pelas atividades de valor". Estas se referem aos processos físicos operacionais utilizados por uma empresa para criar um produto que seja percebido pelo mercado com um determinado valor. A margem representa a diferença entre o valor do produto e os custos das atividades de valor. Com isso, o conjunto de funções empresariais que adicionam valor aos produtos e serviços da organização é denominado cadeia de valor (Value Chain).

A cadeia de valor descreve uma variedade de atividades que devem trazer o produto ou serviço desde sua concepção, através de diferentes fases de produção (implicação de uma combinação de transformação física e a entrada de vários produtos e serviços), entrega aos consumidores finais e disposição final pós-uso (KAPLINSK e MORRIS 2000; KAPLINSK e READMAN, 2001).

A cadeia de valor é composta pelas atividades primárias e de apoio, conforme a Figura 1. As atividades primárias referem-se a atividades envolvidas na criação física do produto, sua venda, transferência ao comprador e assistência pós-venda. Dependendo da empresa, irá variar a importância de cada uma dessas atividades para a obtenção de vantagem competitiva. As atividades de apoio são atividades de suporte às atividades primárias e a elas mesmas. As linhas tracejadas indicam as 
atividades que apóiam as atividades primárias e a cadeia inteira. A infra-estrutura está associada à cadeia de valor inteira (PORTER, 1989).

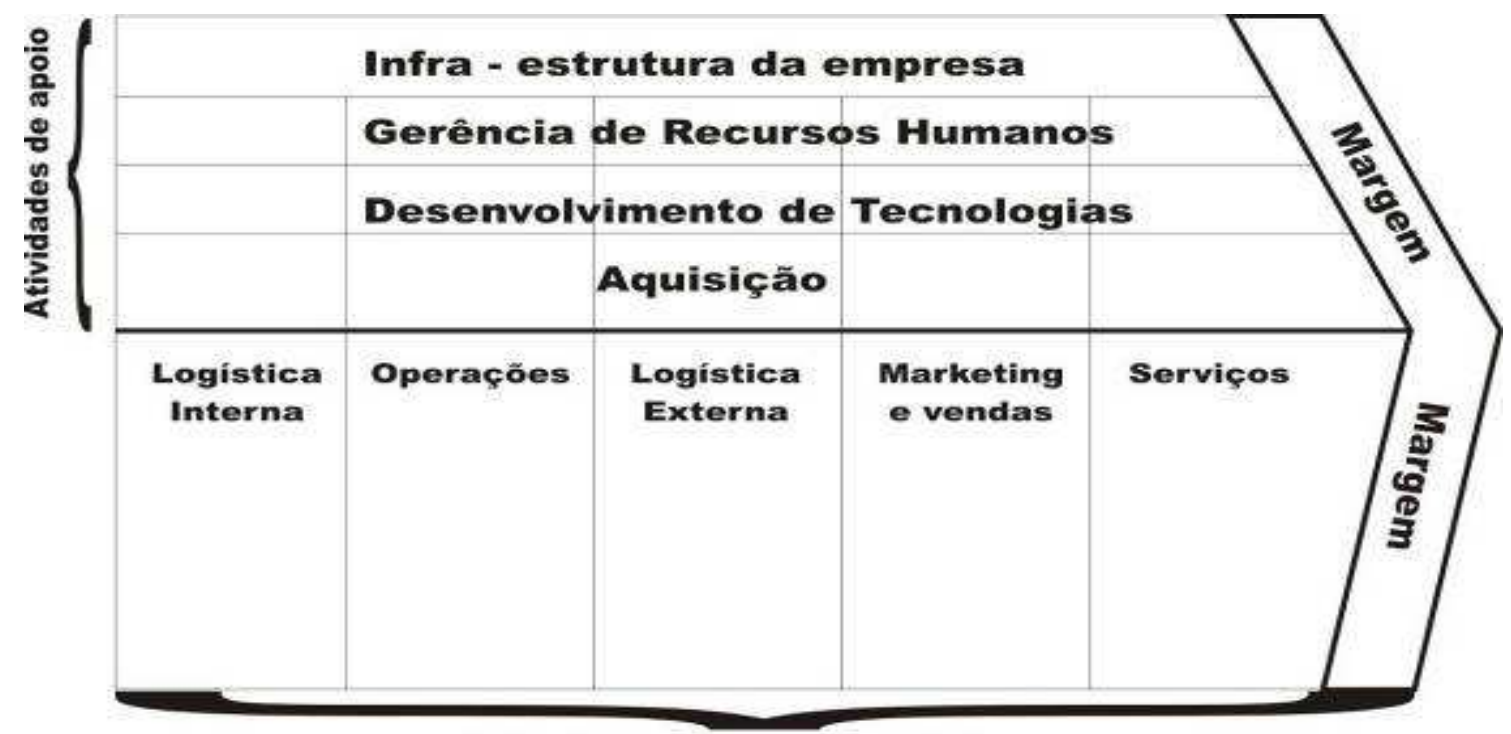

\section{Atividades primárias}

Figura 1 - Cadeia de Valor Genérica Fonte: Porte (1989)

Todavia Kaplinsk e Morris (2000) afirmam que no mundo real, evidentemente, cadeias de valor são muito mais complexas do que isso. Em primeiro lugar, tende a haver muito mais conexões na cadeia. Além das conexões múltiplas, os produtos tipicamente intermediários em uma determinada cadeia de valor podem alimentar-se em um número de cadeias de valor diferentes.

Ohmae (1998) considera como cadeia de valor não apenas as atividades executadas no âmbito de uma empresa, mas a cadeia de valor de um produto, aproximando-se de uma "cadeia produtiva". Pires (2004) Corrobora quando comenta que o modelo proposto por Porter para cadeia de valor "está restrito aos limites internos da empresa".

Dessa forma, uma empresa pode executar apenas algumas atividades de uma cadeia de valor completa. As demais são realizadas em outras organizações com as quais se relacionam, assim, atividades podem ser executadas em vários locais diferentes, fazendo com que as cadeias de valor das empresas apresentem configurações diferentes daquela sugerida por Porter. Dessa forma, Christopher 
(2007) afirma que, o efeito da terceirização é estender a cadeia de valor além dos limites da empresa.

Por outro lado, uma cadeia de suprimentos consiste numa série integrada de atividades, englobando desde o fornecimento das matérias-primas, até a entrega do produto ao consumidor final (BEAMON e WARE, 1998). A cadeia de suprimentos pode também ser descrita como o longo caminho que se estende desde as fontes de matéria-prima, passando pelas fábricas dos componentes, pela manufatura do produto, pelos distribuidores, e chegando finalmente ao consumidor através do varejista (NOVAES, 2001),

Para Christopher (2007) cadeia de suprimentos é a rede de organizações envolvidas, por meio de vínculos a montante e a jusante, nos diferentes processos e atividades que produzem valor na forma de produtos e serviços destinados ao consumidor final.

A estreita relação entre cadeia de valor e cadeia de suprimentos é evidenciada comparando seus conceitos. Numa cadeia de valor "as atividades de valor estão relacionadas por meio de elos dentro da cadeia de valor" (PORTER, 1989 e HANSEN e MOVEN, 2001). Já na cadeia de suprimentos "é a rede de organizações envolvidas, por meio de vínculos a montante e a jusante, nos diferentes processos e atividades que produzem valor na forma de produtos e serviços destinados ao consumidor final" (CHRISTOPHER, 2007; TAYLOR, 2005; PIRES, 2004 e CHOPRA 2003). Desse modo, constata-se a relação entre cadeia de valor e de suprimentos, verificando que ambas partem da mesma filosofia de formação.

\subsection{Evoluindo da cadeia de valor para cadeia de suprimentos}

A cadeia de suprimentos é um subconjunto da cadeia de valor estendida, a qual é focada em agregar valor a um serviço ou a um produto físico, enquanto a cadeia de suprimentos focaliza principalmente a produção, distribuição e vendas de produtos físicos (SIMCHI-LEVI et al., 2000).

Chopra e Meindl (2003) afirmam que, o objetivo central das cadeias de suprimento é maximizar o valor global gerado, sendo este, a diferença entre o valor 
do produto final para o cliente e os esforços de produção realizados pelas empresas para atender ao seu pedido.

Já o objetivo do modelo de cadeia de valor é identificar os principais fluxos de processos dentro de uma organização. O modelo é essencialmente um fluxograma de processos específicos de alto nível, interligados para mostrar fluxos de processo, os quais podem ainda ser divididos em subprocessos e suas atividades de apoio (OSTRENGA et al, 1997).

De acordo com Morais (2008) a abordagem de Cadeia de Valor pode ser aplicada na análise de competitividade de uma empresa, focando sua estruturação interna. O conceito de Cadeia de Suprimentos é utilizado para a análise de uma empresa (focal) no contexto de várias empresas com as quais se relaciona, buscando o entendimento desses relacionamentos, desde o início da cadeia (primeiro fornecedor) até o final da cadeia (cliente final). Em geral o que se espera ao estudar a Cadeia de Suprimentos é o entendimento da mesma, sob a perspectiva da empresa focal.

Nessa discussão entre cadeia de valor e cadeia de suprimentos Porter (1989) apresenta outro conceito que é o de "Sistema de Valores", que compreende uma corrente de diversas cadeias de valores (internas), sob o ponto de vista de uma empresa, e seus elos "corrente acima" e "corrente abaixo", representando respectivamente as cadeias de valor dos fornecedores e dos canais de distribuição e clientes. Na seqüência a Figura 2 mostra a representação gráfica de um sistema de valor.

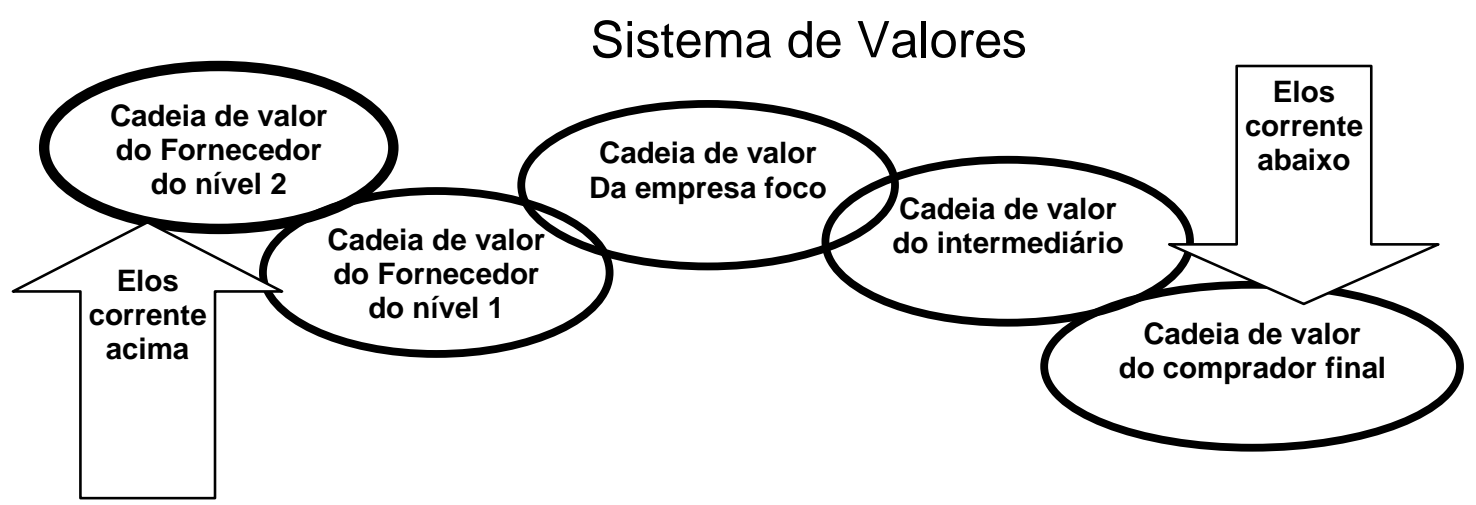

Figura 2 - Representação de Um Sistema de Valores

Fonte: Adaptado de Porter (1989) 
Ohmae (1998) comenta que uma empresa pode manter apenas as capacidades centrais (core competences), e algumas atividades que tradicionalmente faziam parte da sua cadeia de valor podem ser confiadas a terceiros e eliminadas de sua cadeia de valor, passando a relacionar-se com a empresa através do sistema de valores do qual faz parte.

Assim, uma cadeia de suprimentos é formada por uma seqüência de diversas cadeias de valores (empresas). Embora as atividades de valor sejam os elementos chave da vantagem competitiva, a cadeia de valor não é um conjunto de atividades independentes, e sim um sistema de atividades interdependentes (NOVAES, 2001).

Lambert, Stock e Vantine (1999) apud Gasparetto (2003) afirmam que a cadeia de suprimentos é "a extensão e integração da cadeia de valor para várias empresas". Da mesma forma, Farias (2009) comenta que a cadeia de valor é muito confundida com a cadeia de suprimentos quando, na realidade, a cadeia de suprimentos está inserida na cadeia de valor estendida de uma empresa focal.

Diante dessas modificações nos sistemas produtivos, o modelo de cadeia de valor tradicional proposto por Porter na década de 80 passa e dar espaço a formatos estendidos como os comentados por Ohmae (1998). Dessa forma, em função dos processos compartilhados e da expansão geográfica dos sistemas produtivos, 0 processo de formação das cadeias de suprimentos vem sendo norteado pela expansão das cadeias de valor além das barreiras da empresa focal.

\subsection{Estrutura da Cadeia de Suprimentos}

A descrição de uma cadeia de suprimentos deve ser feita a partir de uma empresa, denominada "empresa focal" ou "empresa foco". Os membros da cadeia de suprimentos compreendem, nessa visão, todas as organizações com as quais a empresa focal interage direta ou indiretamente através de seus fornecedores ou clientes, desde o ponto de origem até o ponto de consumo (LAMBERT et al., 1998). Desse modo, há três dimensões estruturais de uma cadeia de suprimentos, conforme mostra o quadro 1. 


\begin{tabular}{|c|l|}
\hline Dimensões & \multicolumn{1}{c|}{ Definição } \\
\hline Estrutura horizontal & Número de níveis da cadeia de suprimentos. \\
\hline Estrutura vertical & Número de empresas em cada nível. \\
\hline $\begin{array}{c}\text { Posição horizontal da } \\
\text { empresa foco dentro da } \\
\text { cadeia de suprimentos }\end{array}$ & $\begin{array}{l}\text { A empresa focal pode estar próxima das fontes } \\
\text { iniciais de suprimentos, próxima dos clientes finais, } \\
\text { ou em alguma posição entre os pontos finais da } \\
\text { cadeia. }\end{array}$ \\
\hline
\end{tabular}

Quadro 1- estrutura da Cadeia de Suprimentos

Fonte: Adaptado de Lambert \& Pohlen (2001).

Após analisar a estrutura da cadeia de suprimentos identificando seus membros, é preciso classificá-los, pois, a gestão estratégica da cadeia de suprimentos depende da função de cada membro dentro da cadeia. Os membros de uma cadeia de suprimentos podem ser classificados como primários ou de apoio.

Membros primários: aquelas organizações ou unidades estratégicas de negócios (SBUs) que executam atividades com valor agregado - operacionais ou gerenciais em processos empresariais projetados para produzir uma saída específica para um cliente particular ou para o mercado (LAMBERT; et al. 1998; LAMBERT \& POHLEN, 2001).

Membros de apoio: são empresas ou SBUs que fornecem recursos, conhecimento, utilidades ou ativos para os membros primários da cadeia de suprimentos, mas que não participam diretamente na execução de atividades nos processos de valor agregado, nos quais há transformação de entradas em saídas para os clientes finais (LAMBERT, et al, 1998), como empresas que alugam caminhões para o fabricante, bancos que emprestam dinheiro para o varejista, empresas que fornecem espaço em armazéns, empresas que fornecem equipamentos para a produção, panfletos para o marketing e outras (LAMBERT \& POHLEN, 2001).

A classificação dos membros da cadeia de suprimentos deve ser norteada por meio das atividades de valor que cada empresa executa na cadeia de valor do produto. Dessa forma, é possível identificar os esforços que cada membro executa na cadeia de suprimentos para promover a produção e liberação do produto ao cliente final.

Para Suppy Chain Council (SCC) (2004) a cadeia de suprimentos abrange todos os esforços envolvidos na produção e liberação de um produto final, desde o 
primeiro fornecedor do fornecedor até o último cliente do cliente. Quatro processos básicos definem tais esforços:

- Planejar (Plan) - Compreende o desenvolvimento e a comercialização de produtos bem como a gestão de demanda.

- Abastecer (Source) - Gerenciamento da relação com fornecedores.

- Fazer (Make) - Gerenciamento do fluxo de produção (Manufatura do Produto)

- Entregar (Delivery) - Gerenciamento da relação com clientes, Gerenciamento do serviço aos clientes e Atendimento dos pedidos.

Os esforços envolvidos na produção e liberação dos produtos na cadeia de suprimentos influenciam e são influenciados pelo formato assumido pela cadeia de valor. Esses esforços devem variar de acordo com a execução das atividades de valor da empresa focal que podem ser conduzidos pela cadeia de valor.

Com isso, observa-se que o estudo da cadeia de valor é capaz de nortear, além da formação da cadeia de suprimentos, seu funcionamento por meio do mapeamento dos esforços envolvidos na produção e liberação dos produtos aos clientes finais, o que enfatiza a estreita relação entre cadeia de valor e cadeia de suprimentos.

\section{PROCEDIMENTOS METODOLÓGICOS}

Esta pesquisa foi desenvolvida a partir de um estudo teórico sobre: cadeia de valor e cadeia de suprimentos. Em seguida, foi realizado um estudo exploratório e descritivo em uma empresa do setor de comunicação e mídia da cidade de João Pessoa (PB), onde foi feita a coleta de dados através de medições "in loco" e entrevistas estruturadas conforme a literatura pesquisada. A partir da análise do processo de produção de um produto denominado nesse trabalho por Revista, pretende-se mostrar como a análise da cadeia de valor desse produto pode auxiliar na formação da cadeia de suprimentos dessa empresa. 


\subsection{Ambiente da Pesquisa}

O ambiente de pesquisa é composto de três empresas: a empresa focal e seu cliente e fornecedor mais relevante. No Quadro 2, na seqüência, serão descritas as características básicas de cada uma dessas empresas:

\begin{tabular}{|c|c|c|c|}
\hline & Fornecedor & Empresa Focal & Cliente \\
\hline $\mathbf{N}^{\circ}$ de Funcionários & $\begin{array}{c}330 \\
\text { funcionários }\end{array}$ & 38 colaboradores & 459 servidores \\
\hline $\begin{array}{c}\text { Segmento de } \\
\text { atuação }\end{array}$ & $\begin{array}{c}\text { Gráfico e } \\
\text { editorial }\end{array}$ & $\begin{array}{c}\text { Agência de noticias, } \\
\text { Jornalismo. }\end{array}$ & $\begin{array}{c}\text { Contas } \\
\text { Públicas }\end{array}$ \\
\hline Tempo de atuação & 43 anos & 7 anos & 37 anos \\
\hline $\begin{array}{c}\text { Produtos e } \\
\text { Serviços }\end{array}$ & $\begin{array}{c}\text { Editoração e } \\
\text { impressão de } \\
\text { alta qualidade }\end{array}$ & $\begin{array}{c}\text { Assessoria de } \\
\text { Comunicação, Cobertura } \\
\text { Jornalística e Transmissão } \\
\text { de Eventos On-line, } \\
\text { Produção de Sports e } \\
\text { Revista. }\end{array}$ & $\begin{array}{c}\text { Auditoria e } \\
\text { transparência } \\
\text { pública. }\end{array}$ \\
\hline
\end{tabular}

Quadro 2 - Caracterização das empresas que participaram da pesquisa Fonte: Elaborado pelos autores

Fornecedor: No início com uma pequena tipográfica manual, hoje, a Gráfica possui um dos maiores e mais modernos parques gráficos do Brasil e a maior rede de atendimento. Dispõem de equipamentos de última geração, recursos dos mais variados e, o mais importante, uma equipe pronta para satisfazer o cliente. A Gráfica sempre privilegiou o constante investimento em atualização tecnológica, tanto através do desenvolvimento de seus profissionais, participando de treinamentos, visitas, congressos e feiras no Brasil e exterior, como também através da aquisição de novos e modernos equipamentos, práticas que situaram a empresa como uma das mais desenvolvidas e modernas do mercado gráfico nacional.

Empresa Focal: Conquistou espaço no mercado da comunicação pela credibilidade e pela qualidade dos produtos oferecidos. No início da sua história, o grupo era responsável por fazer consultas mercadológicas, avaliações e planejamento de comunicação. A partir de 2001, com a criação de setor de Mídia \& Artes, as atividades foram multiplicadas envolvendo pesquisa de opinião pública, produção cultural e todo o universo da comunicação. Seus primeiros trabalhos estavam 
ligados à produção diária de programas de rádio, com jornalismo dinâmico e plural que servia de base para as informações que davam suporte ao Portal On-line.

Cliente: Todos os esforços da empresa do setor governamental, mais recentemente, visam a dar cumprimento aos elevados encargos que Ihes são reservados pela LRF (Lei de Responsabilidade Fiscal), inaugurando uma nova era na fiscalização e controle externo - deveres/direito que a Constituição Federal Ihe outorga, modificando o momento e a oportunidade do controle, permitindo a tomada de posição e a correção de rumos, aspectos centrais do ideário da LRF.

\subsection{Desenvolvimento da Pesquisa.}

A pesquisa foi desenvolvida conforme descreve o fluxograma, mostrado na Figura 3:

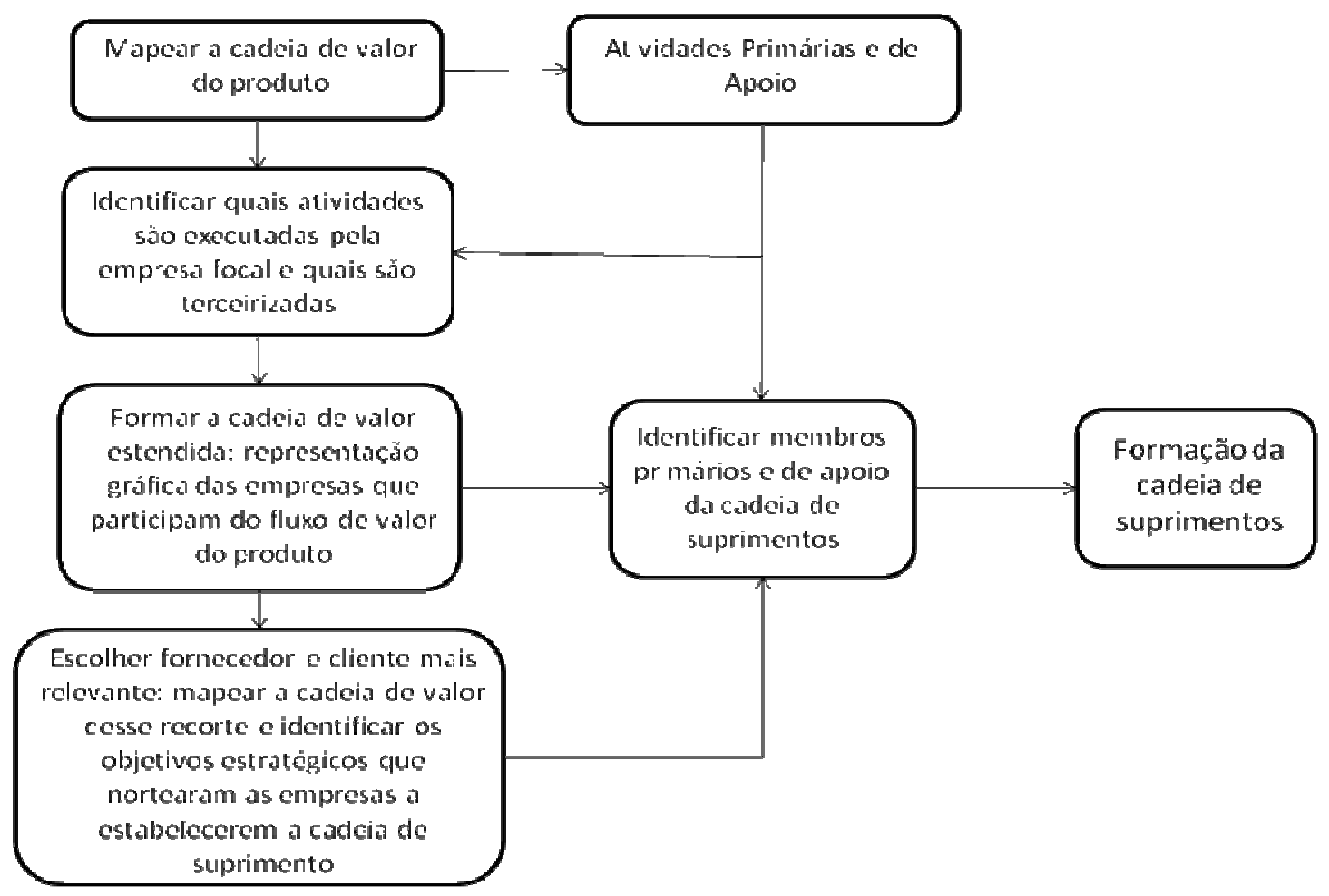

Figura 3 - Fluxograma de desenvolvimento da pesquisa 


\section{FORMAÇÃO DA CADEIA DE SUPRIMENTOS}

A formação da cadeia de suprimentos de um produto passa pelo mapeamento de sua cadeia de valor, uma vez que, de acordo com Simchi-Levi et al, (2000), a cadeia de suprimentos é um subconjunto da cadeia de valor estendida. A Figura 4 mostra o processo de evolução da cadeia de valor para cadeia de suprimentos.

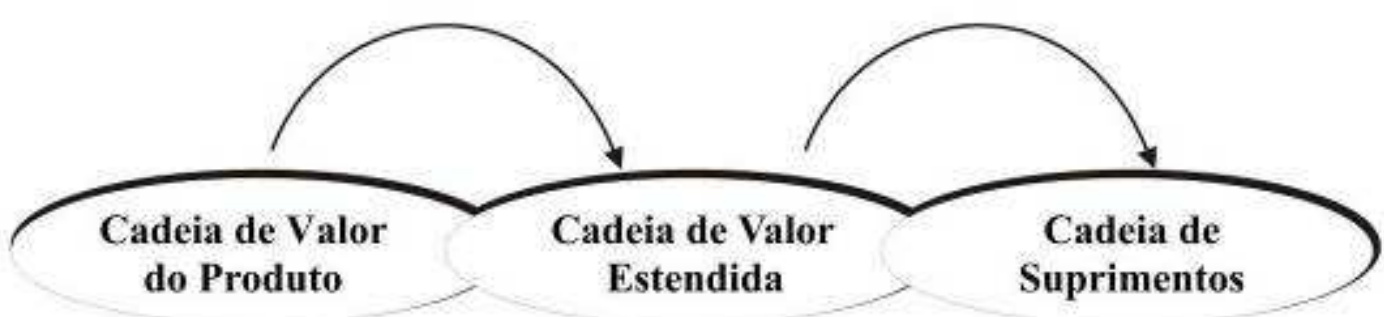

Figura 4 - Evolução da cadeia de valor para cadeia de suprimentos Fonte: Os autores

A cadeia de valor do produto é construída a partir da identificação das atividades de valor do produto confrontando com o modelo genérico proposto por Porter (1989). Com a formação da cadeia de valor do produto, deve-se estabelecer a empresa focal, ou seja, detentora do produto e, consequentemente, construir sua cadeia de valor.

Ao verificar se as atividades de valor são executadas pela empresa focal, ou, distribuídas por uma gama de empresas, é possível definir se a mesma apresenta um formato tradicional ou estendido para sua cadeia de valor. Nesse momento, temse a cadeia de valor do produto em função da empresa focal, que devido a transferência de competências de algumas atividades de valor do produto, pode assumir formatos diferentes do proposto por Porter, apresentando cadeias de valor estendidas, sendo esse um indicio de que as atividades de valor geram a cadeia de suprimentos.

Em um último estágio, com a cadeia de valor do produto estendida em função empresa focal, pode-se construir sua cadeia de suprimentos. Nesse momento, 
verificam-se quais empresas executam atividades de valor do produto, bem como os objetivos estratégicos que nortearam a ligação entre essas empresas. Todavia, essa análise permite a identificação dos membros da primeira camada da cadeia de suprimentos tanto a montante como a jusante, sendo o mapeamento completo da cadeia, norteado nos moldes tradicionais, onde se identifica os fornecedores dos fornecedores e clientes dos clientes.

\subsection{Cadeia de valor do produto e da empresa focal}

O primeiro passo para mapear a cadeia de valor do produto é identificar as atividades de valor que fazem parte do seu processo produtivo, desde a aquisição da matéria-prima até a entrega do produto acabado ao cliente final.

Analisando as atividades que compõe o processo produtivo da Revista e confrontando com o modelo genérico proposto por Porter (1989), pode-se mapear sua cadeia de valor. Ainda nesse momento, é possível identificar as atividades primárias e de apoio.

Com a cadeia de valor do produto definida, o próximo passo é identificar a empresa focal, ou seja, a principal responsável pela produção da Revista. Feita essa identificação, o passo seguinte é definir quais atividades de valor são executadas pela empresa (internamente) e quais têm suas competências transferidas para terceiros. O objetivo dessa análise é verificar se a cadeia de valor da empresa focal se enquadra no modelo tradicional proposto por Porter (1989) ou se assume formato estendido conforme relata Ohmae (1998).

Para Porter (1989) as organizações devem olhar para cada atividade em sua cadeia de valor e avaliar se elas têm uma vantagem competitiva real na atividade. Se não tiverem, talvez devam considerar a terceirização dessa atividade, utilizando um parceiro que possa oferecer essa vantagem de custo ou de valor.

Como o processo produtivo da Revista é descentralizado, com varias empresas executando atividades de valor agregado, a empresa focal apresenta uma cadeia de valor estendida. Na sequência a Figura 5 ilustra a cadeia de valor do produto e da empresa focal. As atividades de valor executadas por terceiros estão destacadas na cadeia de valor do Produto, logo abaixo é ilustrada a cadeia de valor 
da empresa focal, onde estão descritas as empresas e as respectivas atividades que executam para a obtenção da Revista. Cada bloco especifica atividade de valor e empresa responsável pela respectiva atividade, as setas representam a direção do fluxo de valor do produto, onde os membros a montante (parte esquerda) viabilizam bens e serviços fundamentais para edição da revista, ou seja, em grande parte membros de apoio com exceção dos diagramadores. Já a Jusante (parte direita) se concentram os membros primários que executam atividades de valor agregado, como é o caso da aráfica que é responsável pela impressão da revista.

\section{Cadeia de Valor do Produto}
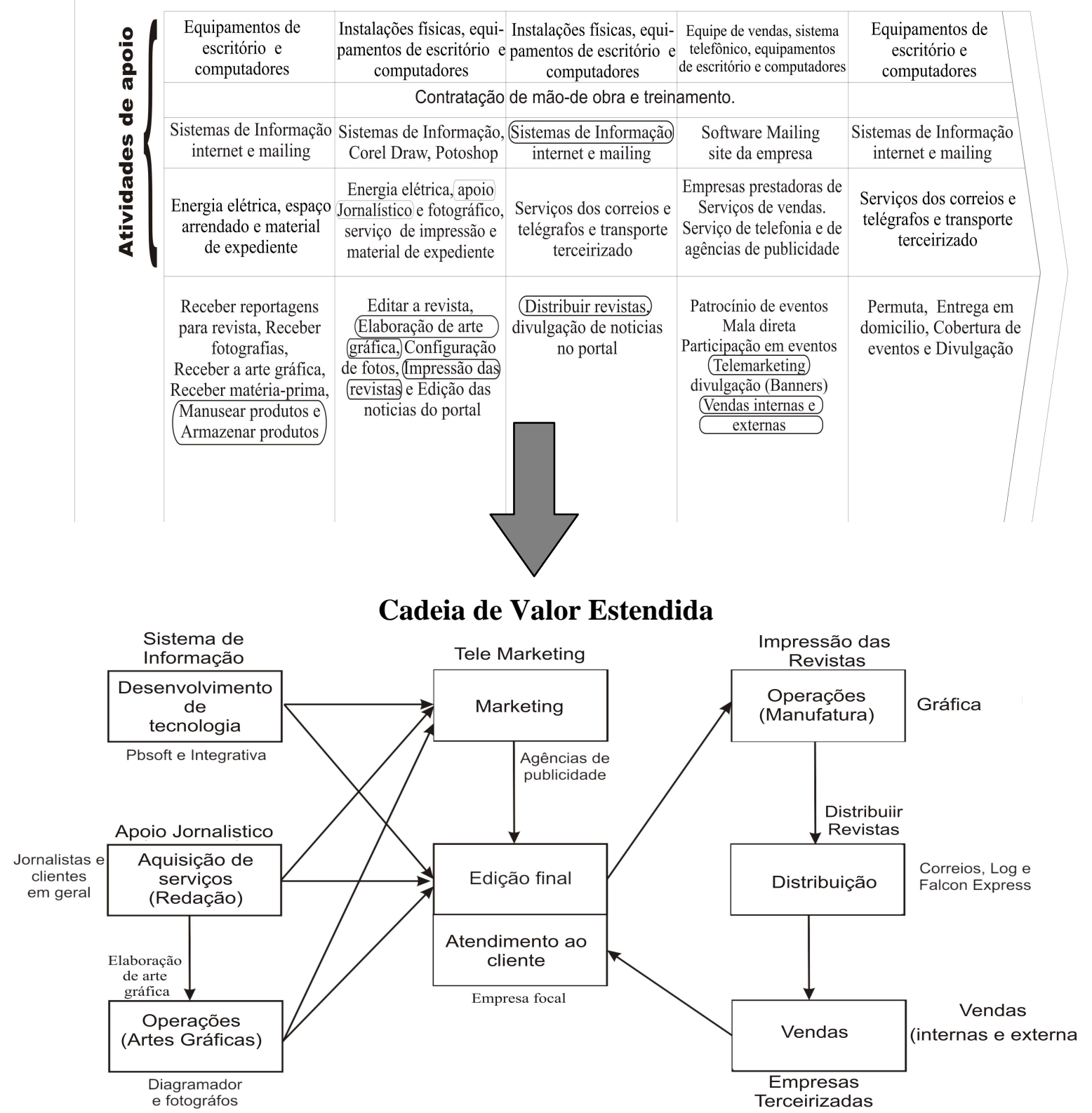

Figura 5 - Cadeia de valor do produto e da empresa focal 
A empresa focal demanda dois produtos: um Portal de Notícias e uma Revista foco desta pesquisa. Na Revista, apenas a edição final e as notícias locais são realizadas nas dependências da empresa, toda cobertura feita nos demais estados do nordeste é delegada a profissionais terceirizados, a manufatura da Revista (editoração e Impressão) são de competência de gráficas de João Pessoa, a arte e as fotos são fornecidas por terceiros e a logística de distribuição da Revista também é de competência de empresas contratadas pela empresa focal e assim por diante. Essa relação entre atividade de valor e seu executor pode ser visualizada na Figura 5, onde os componentes da cadeia de valor estendida (parte inferior da figura) estão destacados da mesma forma que suas respectivas atividades de valor na cadeia de valor do produto (parte superior da figura).

A partir da cadeia de valor da empresa focal e identificação das empresas que executam as respectivas atividades de valor, pode-se definir sua cadeia de suprimentos. Para formar a cadeia de suprimentos as empresas se arranjam de acordo com a compatibilidade de objetivos. Para verificar esse fato é feito um recorte na cadeia de suprimentos, escolhendo um membro a montante (fornecedor) e outro à jusante (cliente).

\subsection{Escolha e análise dos elos da cadeia: Fornecedor e Cliente mais relevante}

O fornecedor escolhido foi uma Gráfica, empresa líder no setor gráfico da grande João Pessoa e principal fornecedor de serviços da empresa. A Gráfica é responsável pela editoração e impressão da Revista. A empresa tem como principais objetivos estratégicos a qualidade, rapidez e confiabilidade, apresentando um alto padrão de qualidade dispondo de máquinas e equipamentos de alta tecnologia e matéria-prima de primeira linha.

Os clientes podem acompanhar o processo produtivo para verificar se a qualidade do serviço corresponde a suas expectativas. Dispõe de vários meios de transporte para fazer a entrega dos produtos, sendo por frota própria e outra parte terceirizada, utiliza vários modais e flexibilidade de prazos de entrega. Esse mix garante a confiabilidade de entrega dos produtos satisfatória para empresa focal. 
O principal produto da Empresa Focal é a Revista que atende a um público exigente. Assim como o conteúdo, a qualidade tangível do produto é fundamental para sua aceitação no mercado. As atividades gráficas como a impressão, são um diferencial do produto que deve apresentar um alto padrão de qualidade. Para executar essa atividade, seria necessário um investimento altíssimo. Com isso, essa atividade foi delegada à Gráfica em função da qualidade de seus serviços, rapidez e confiabilidade de entrega dos produtos.

Após analisar o relacionamento a montante segui-se a jusante da cadeia de suprimentos. O cliente escolhido foi uma empresa do setor governamental, que representa $\circ 12^{\circ}$ lugar em arrecadação entre todos os clientes da Revista. O principal norteador da escolha dessa empresa como cliente relevante foi a compatibilidade de interesses entre a empresa focal e os conselheiros daquela corte de contas.

A empresa do setor governamental tem como principal atividade fazer auditoria das contas em órgãos públicos. A parceria entre a empresa do setor governamental e a empresa focal é estabelecida em função do serviço que ela oferece, ou seja, a informação e apoio jornalístico que a Revista proporciona, sendo fundamental para os membros do conselho dessa empresa, que são os beneficiários da aquisição desse produto.

A Revista sempre enfatiza a política e economia regional, o conhecimento desse tipo de informação é fundamental para o desempenho das funções institucionais dos conselheiros, que precisam tomar decisões estruturadas em análises qualitativas. Desse modo, é preciso estar informado e atualizado sobre o que ocorre na política e economia local.

Para mostrar como essas empresas formaram seus elos, foi mapeada a cadeia de valor de cada uma delas. Com isso, foram identificados os objetivos estratégicos $e$ as atividades de valor para saber o que norteou essa ligação. A Figura 6 apresenta o mapeamento da cadeia de valor do Fornecedor, Revista e Cliente. É evidenciada a ligação entre as empresas por meio das atividades de valor que tiveram suas competências essenciais transferidas e por esse motivo promoveram essa ligação. 


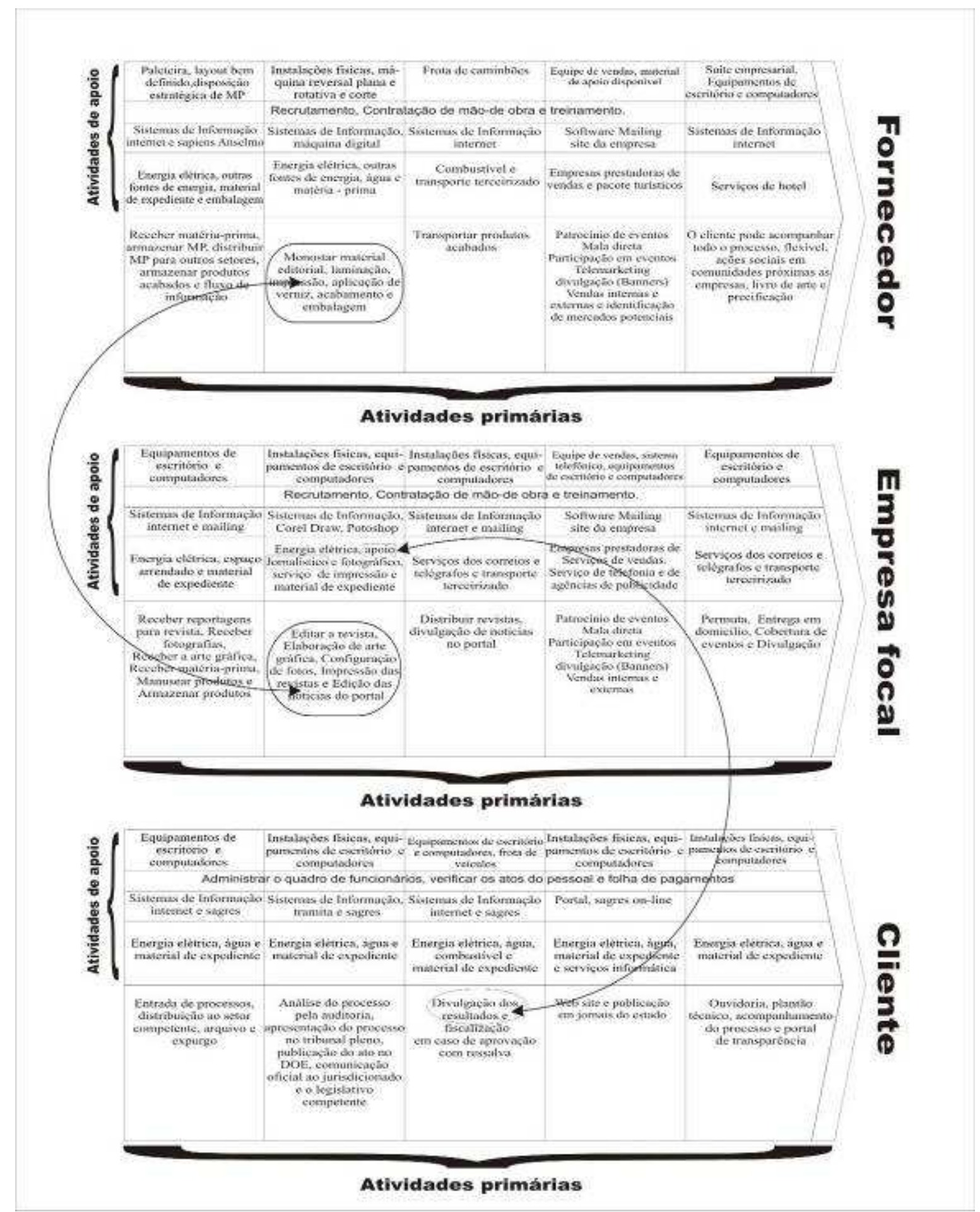

Figura 6 - Relação entre Fornecedor, Revista e cliente

A Figura 6 mostra as atividades de valor que nortearam a ligação entre fornecedor, empresa focal e cliente. O estudo da cadeia de valor, além de identificar os objetivos estratégicos e as atividades de valor que nortearam a formação da 
cadeia de suprimentos, pode promover a classificação dos membros da cadeia de suprimentos de acordo com as atividades de valor executada por cada empresa na cadeia de suprimento que pode ser primária ou de apoio.

\subsection{Identificação dos membros primários e de apoio da Cadeia de Suprimentos}

Para identificar os membros primários e de apoio da cadeia de suprimentos, deve-se localizar a empresa na estrutura da cadeia de valor da empresa focal, identificar a atividade de valor e qual sua função na cadeia de valor do produto. Na seqüência o Quadro 3 apresenta os membros primários e de apoio da cadeia de suprimentos.

\begin{tabular}{|c|c|c|c|}
\hline $\begin{array}{l}\text { Empresa da } \\
\text { Cadeia de } \\
\text { Valor }\end{array}$ & Atividade de Valor & $\begin{array}{c}\text { Função na Cadeia } \\
\text { de valor do } \\
\text { Produto. }\end{array}$ & $\begin{array}{c}\text { Membro da } \\
\text { Cadeia de } \\
\text { Valor }\end{array}$ \\
\hline GSM & Impressão da revista & \multirow[b]{2}{*}{ Operações } & \multirow{7}{*}{ Primário } \\
\hline $\begin{array}{l}\text { Profissionais } \\
\text { de design } \\
\text { gráfico } \\
\end{array}$ & Fornecem artes gráficas & & \\
\hline Log e Express & Distribuicão da Revista Nordeste & \multirow{3}{*}{ Logística Externa } & \\
\hline $\begin{array}{l}\text { Falcon } \\
\text { Express }\end{array}$ & para pessoa jurídica & & \\
\hline Correios & \begin{tabular}{|c} 
Distribuição da Revista Nordeste \\
para pessoa física
\end{tabular} & & \\
\hline $\begin{array}{c}\text { Empresa de } \\
\text { Vendas }\end{array}$ & Vendas externas dos produtos & \multirow[b]{2}{*}{ Marketing e Vendas } & \\
\hline $\begin{array}{c}\text { Empresa de } \\
\text { Tele } \\
\text { marketing } \\
\end{array}$ & Atendimento ao cliente & & \\
\hline Clientes & Aquisição de informação & \multirow{4}{*}{ Aquisição } & \multirow{8}{*}{ Apoio } \\
\hline Gráfica JB & Imoressão de folder & & \\
\hline Copiadora PB & & & \\
\hline $\begin{array}{l}\text { Jornalistas e } \\
\text { Fotógrafos }\end{array}$ & $\begin{array}{l}\text { Cobertura jornalística de outros } \\
\text { estados. }\end{array}$ & & \\
\hline PBSOFT & Desenvolvimento de software de & \multirow{4}{*}{$\begin{array}{l}\text { Desenvolvimento de } \\
\text { Tecnologia }\end{array}$} & \\
\hline Pratica & $\begin{array}{c}\text { controle administrativo e } \\
\text { financeiro } \\
\end{array}$ & & \\
\hline Ativa Web & Desenvolvimento de website & & \\
\hline Integrativa & Monitoramento da revista on-line & & \\
\hline
\end{tabular}

Quadro 3 - Membros Primários e de apoio da cadeia de suprimentos 
Observa-se que em geral os membros primários e de apoio da cadeia de suprimentos executam respectivamente atividades primárias e de apoio na cadeia de valor do produto. Identificada a função dos membros que estão diretamente ligados a empresa focal, segue-se mapeando toda a cadeia de suprimentos, desde a origem da matéria-prima até o cliente final.

\subsection{Mapeamento da Estrutura completa da cadeia de Suprimentos}

Para mapear a estrutura completa da cadeia de suprimentos é preciso identificar os fornecedores dos fornecedores e cliente dos clientes. Com isso, consegue-se identificar os fornecedores desde a origem da matéria-prima até o cliente final, geralmente, o varejo.

A cadeia de suprimentos completa da empresa focal é composta de 5 níveis a montante e 2 níveis a jusante. A empresa focal se encontra à dois níveis do consumidor final (Varejo). Na seqüência a Tabela 1 apresenta em síntese dados a respeito da estrutura da cadeia de suprimentos mostrando o número de níveis à montante e à jusante, bem como o número de membros em cada nível.

Tabela 1 - Estrutura da Cadeia de Suprimentos

\begin{tabular}{|c|c|c|c|c|c|c|c|c|}
\hline Nível & 5 & 4 & 3 & 2 & 1 & \multirow{3}{*}{$\begin{array}{l}\text { Empresa } \\
\text { Focal }\end{array}$} & 1 & 2 \\
\hline Localização & \multicolumn{5}{|c|}{ Montante (Fornecedores) } & & \multicolumn{2}{|c|}{$\begin{array}{l}\text { Jusante } \\
\text { (Clientes) }\end{array}$} \\
\hline $\begin{array}{c}N^{\circ} \text { de } \\
\text { Membros }\end{array}$ & 2 & 8 & 13 & 16 & 1 & & 17 & 1 \\
\hline
\end{tabular}

Após localizar a empresa focal na cadeia de suprimentos, identificar o número de níveis a jusante e a montante e o número de empresa em cada nível, pode-se representa-la conforme mostra a Figura 7 que apresentada a diagramação da cadeia de suprimentos da empresa focal. 


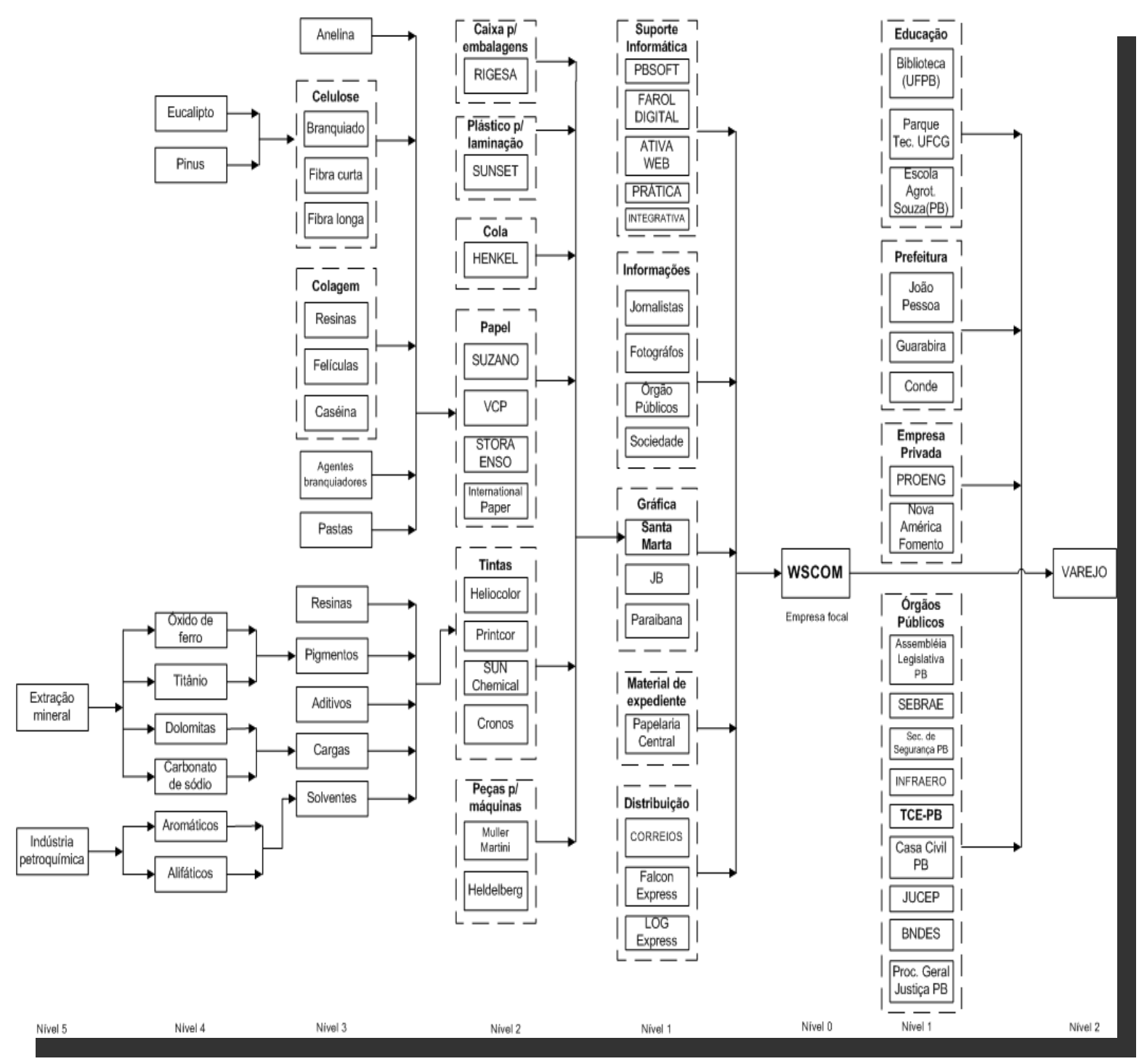

Figura 7 - Cadeia de Suprimentos da empresa Focal.

Fonte: Elaborado pelos Autores

\subsection{Processos básicos da cadeia de suprimentos.}

A cadeia de suprimentos abrange todos os esforços envolvidos na produção e liberação de um produto final, desde o primeiro fornecedor do fornecedor até o último cliente do cliente. Para entender como a cadeia de suprimento executa suas tarefas é preciso entender como cada membro da cadeia de suprimentos coopera para a efetividade da produção de bens e serviços demandados. Os quatro processos básicos que definem tais esforços são: 
Planejar: O planejamento das atividades da cadeia de suprimentos é realizado pela empresa focal, apesar de várias atividades serem executadas além das fronteiras da empresa, a edição da Revista é realizado pela própria empresa. Esse fato comprova que ela é realmente a empresa focal. A empresa orientada pelo mercado estabelece o escopo da revista, sendo responsável pela geração de demanda, planejamento e gerenciamento de todas as atividades envolvidas no processo de produção da Revista, desde as atividades executadas pela mesma até as que envolvem os demais membros da cadeia de suprimentos.

Abastecer: $O$ relacionamento com os fornecedores provê a estrutura para criação e manutenção de relacionamentos. Há uma reciprocidade entre a empresa focal e seus fornecedores e clientes, onde a empresa focal recebe insumos e serviços de seus fornecedores e ao mesmo tempo pode prestar serviços aos mesmos. A Figura 8 ilustra o fluxo de serviços entre os membros da cadeia de suprimentos. A empresa focal trabalha com informação e executa a edição final da Revista, bem como, cobre os acontecimento e eventos do estado. Porém, nos demais estados existem equipes de fotógrafos e jornalistas, alguns enquadrados como pessoa jurídica com escritório próprio e outros como autônomo. Esses fornecem imagens e informações para a edição final da Revista A empresa também é abastecida pela papelaria central que fornece material de expediente. Além disso, os clientes podem fornecer informações para edição de noticias, em geral, os órgãos públicos. Nesse momento, observa-se que um cliente em um dado momento pode exercer o papel de fornecedor na cadeia de suprimentos. 


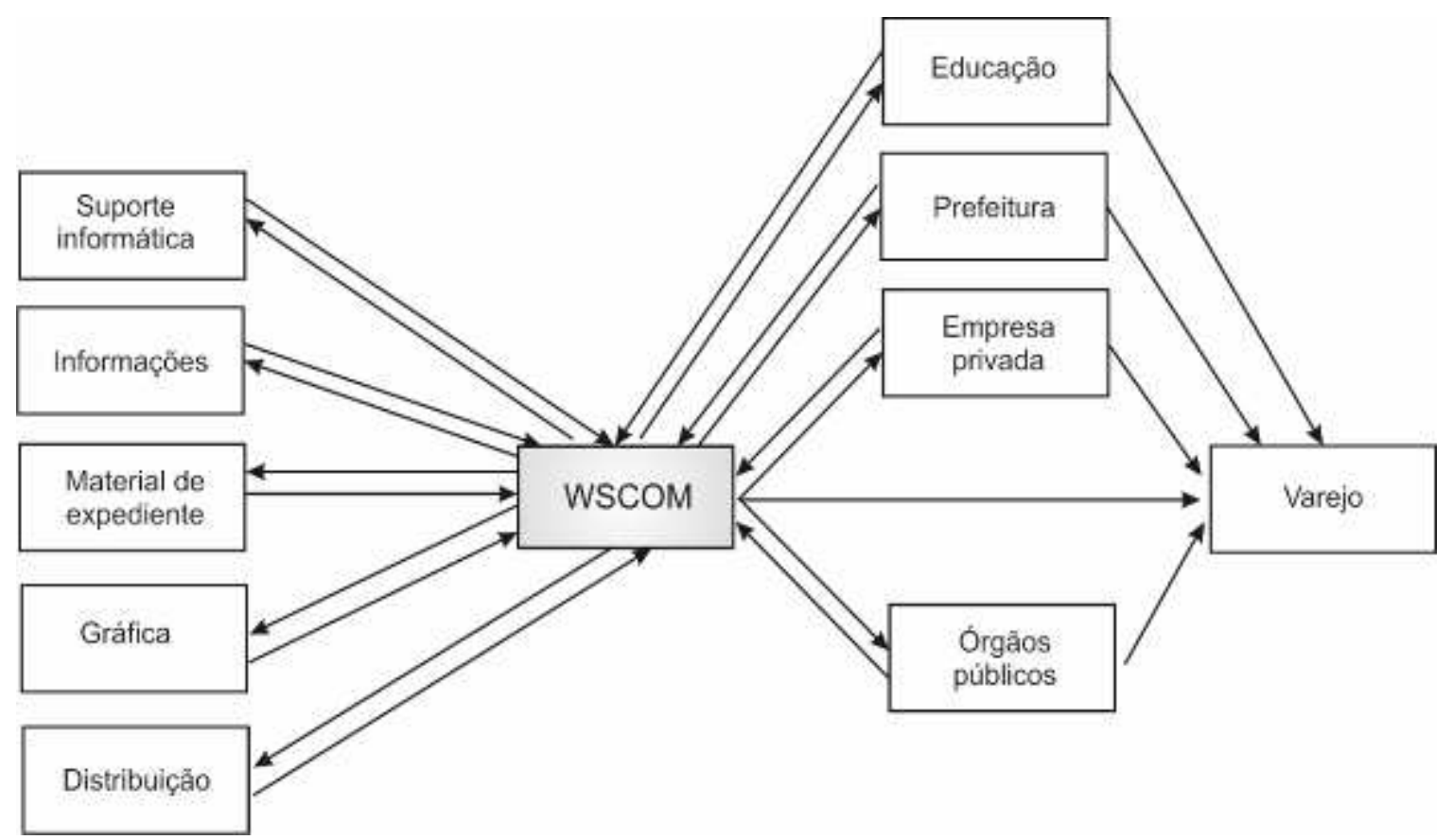

Figura 8 - Fluxo de abastecimento de bens e serviços entre a empresa focal e os membros da cadeia de Suprimentos

Fabricar - O fluxo de produção é controlado pela empresa focal e por cada empresa que executa atividades diretamente relacionadas à produção da revista. Como por exemplo, a gráfica que executa a impressão da Revista e os fotógrafos e jornalistas que participam da edição das noticias.

Entregar - Objetiva atender necessidades dos clientes em vários aspectos como quantidade, prazos e qualidade. No que tange a entrega do produto final e serviços aos clientes, cabe as empresas terceirizadas gerenciar suas atividades, sendo elas, gerenciadas ou não pela empresa focal. Esse processo é realizado em grande parte pelos Correios e Telégrafos, tanto para pessoa física como para pessoa jurídica. A Falcon Express e Log Express trabalham como distribuidores. A Log Express faz cobertura apenas nos estados onde a Falcon Express não atua (Distrito Federal e Rio de Janeiro). 


\section{CONSIDERAÇÕES FINAIS}

A desverticalização do processo produtivo expande as atividades de valor para várias empresas, assim, a cadeia de valor assume configurações diferentes das tradicionais, onde a empresa executa todas as atividades do processo produtivo.

Com a visão da cadeia de valor da empresa, o foco é centrado em suas atividades essenciais. Essas atividades são aquelas que a empresa tem competência para desempenhar, seja pela produtividade em suas operações ou porque a tecnologia utilizada é própria e ainda não é de senso comum. As demais atividades são terceirizadas, sendo da responsabilidade de parceiros de negócios, cujas operações são subordinadas por coordenação daquele que tem poder para isso. Esses parceiros, por sua vez, têm competência para atuar nessas atividades, que para eles são essenciais, considerando a cadeia de valor estendida de seus produtos.

A cadeia de suprimentos da empresa focal foi construída a partir das necessidades de se aliar a outras empresas para viabilizar a produção da Revista e demais produtos da empresa focal, atendendo aos objetivos estratégicos exigidos pelo mercado. A expansão das atividades da cadeia de valor da empresa focal foram as norteadoras da formação de sua cadeia de suprimentos. Assim, a cadeia de valor da empresa focal se transformou na cadeia de suprimentos.

A estreita relação entre cadeia de valor e cadeia de suprimentos é enfatizada no momento em que se verifica que varias empresas estão inseridas no processo de agregação de valor da Revista e que as atividades executas por essas empresas são compatíveis com as atividades de valor do produto. Nesse momento foi possível, inclusive, identificar os membros primários e de apoio da cadeia de suprimentos em função da cadeia de valor da empresa focal e do produto.

O estudo da cadeia de valor do recorte da cadeia de suprimentos também contribui para consolidar essa assertiva Analisando a Figura 5 observa-se que há pelo menos uma atividade de valor compatível entre as empresas que estabelecem a ligação entre as mesmas, ainda, durante essa análise é possível constatar que as empresas do elo estudado apresentam objetivos estratégicos compatíveis entre si, o que consolida ainda mais o compartilhamento de processos entre elas. 
Até mesmo as empresas reconhecem que a ligação entre elas foi estabelecida em função da transferência de competência efetuada. Como e o caso da impressão da Revista, atividade que estabeleceu a ligação entre a empresa focal e uma gráfica da cidade de João Pessoa. Os gerentes do setor de Logística de ambas as empresas concordam com essa assertiva e afirma ser comum esse procedimento, principalmente a empresa focal.

Analisando os processos básicos da cadeia de suprimentos, observa-se que o processo de fabricação é apoiado por um considerável número de membros da cadeia, isso reforça o enfoque da cadeia de valor da empresa focal na terceirização de suas atividades principais, a fim de atingir vantagem competitiva, o que evidencia o fato da cadeia de valor da mesma ser estendida.

A partir da análise da cadeia de valor é que se percebe como o processo de planejamento é concentrado na empresa focal. Com a terceirização de grande parte do processo produtivo a empresa focal é detentora dos produtos demandados, com isso, podem se concentrar em planejar e gerenciar seus parceiros.

Outro fato que demonstra que a cadeia de valor da empresa focal é estendida, pode ser evidenciado pelo fato de sua cadeia de suprimentos apresentar um grande número de membros primários, ou seja, varias empresas executando atividades de valor agregado. Existem também muitos membros de apoio, estes exercem um importante papel na cadeia de suprimentos dando suporte a empresa focal e por muitas vezes as demais membros primários da cadeia de suprimento 0 que promove uma agilidade no processo produtivo da revista.

Este artigo mostrou a estreita relação entre cadeia de valor e cadeia de suprimentos. A formação da cadeia de suprimentos por meio do estudo da cadeia de valor da empresa focal realizada neste artigo, consolida a afirmação de (SIMCHILEVI et al., 2000) "A cadeia de suprimentos é um subconjunto da cadeia de valor"

Os novos conceitos de cadeia de valor e cadeia de suprimentos são reflexos das novas estruturas e processos com os quais as organizações procuram se preparar estrategicamente. Dessa forma, estudos sobre cadeia de suprimentos como vantagem competitiva devem ganhar cada vez mais espaço, em virtude das modificações e aumento da complexidade dos produtos e processos produtivos. 


\section{REFERÊNCIAS}

BEAMON, B. M.; WARE, T. M. A process quality model for the analysis, improvement and control of supply chain system. International Journal of Physical Distribution \& Logistics, v. 28, 1998.

BRIMSON, J. A. Contabilidade por atividade. São Paulo: Atlas, 1996.

CHIAVENATO, I. SAPIRO, A. Planejamento estratégico: fundamentos e aplicações. Rio de Janeiro: Elsevier, 2003.

CHOPRA, S.; MEINDL, P. Gerenciamento da cadeia de suprimentos: estratégias, planejamento e operação. São Paulo: Person, 2003.

CHRISTOPHER, M. Logística e gerenciamento da cadeia de suprimentos: criando redes que agregam valar. 2. ed. São Paulo: Thomson Learning, 2007.

FARIAS, L. J., A importância da cadeia de valor para o desenvolvimento das organizações, 2009, [Produção Científica]. [on line]: Disponível em $<$ www.administradores.com.br/artigos/12314> acesso em: 05/03/2009

GASPARETTO, V. Proposta de uma sistemática para avaliação de desempenho em cadeias de suprimentos. Florianópolis, Tese (Doutorado) - Universidade Federal de Santa Catarina, UFSC, 2003.

HANSEN, D. R; MOVEN, M. M, Gestão de custos: contabilidade e controle. São Paulo: Pioneira, 2001.

LAMBERT, D.M.; COOPER, M.C.; PAGH, J.D. Supply chain management: implementation issues and research opportunities. The international Journal of Logistics Management, v.9, no 2, p. 1-19, 1998.

LAMBERT, D. M.; POHLEN, T. L. Supply chain metrics. The International Journal of Logistics Management, 2001.

LEITE, M. S. A. Proposta de uma modelagem de referência para representar sistemas complexos. 2004. Tese (Doutorado em Engenharia de Produção) Programa de Pós-Graduação em Engenharia de Produção, Universidade Federal de Santa Catarina, Florianópolis, 2004.

KAPLINSK R.; MORRIS M., An Important health warning or a guide for using this handbook. In: BELLAGIO WORKSHOP, set. 2000.

KAPLINSKY, R; MORRIS, M; READMAN, J. The globalization of product markets and immiserisiing growth: lessons from the south African furniture industry. Brighton: University of Sussex/IDS/CRIM, 2001. 
MORAIS, M. A C. Proposta de um modelo para análise de cadeias de suprimentos de usinas siderúrgicas: estudo de caso na ARCELORMITTAL TUBARÃO aços planos. 2008. Dissertação (Dissertação em Engenharia de Produção) - Programa de Pós-Graduação em Engenharia de Produção, Universidade Federal da Paraíba, João Pessoa, 2008.

NOVAES, A. G. Logística e gerenciamento da cadeia de distribuição: estratégia, operação e avaliação. Rio de Janeiro: Campus, 2001.

OHMAE, K. Os novos limites da empresa. HSM Management, 1998.

OSTRENGA, M. Guia da Ernst \& Young para gestão total dos custos. Rio de Janeiro: Editora Record, 1997.

PIRES, S R. I. Gestão da cadeia de suprimentos: conceitos, estratégias, práticas e casos. São Paulo: Atlas, 2004.

PORTER, M. E. Vantagem competitiva. Rio de Janeiro: Campus, 1989.

SCC (SUPPLY CHAIN COUNCIL). Supply-chain operations reference - model. Versão 6.0. SCC: Pittsburgh, 2004.

SIMCHI-LEVI, D.; KAMINSKY, P.; SIMCHI-LEVI, E. Designing and managing the supply chain. McGraw-Hill, 2000.

TAYLOR, David A. Logística na Cadeia de Suprimentos: uma perspectiva gerencial. São Paulo: Pearson Addison-Wesley, 2005.

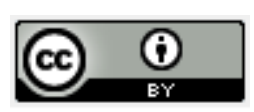

Artigo recebido em 27/07/2009 e aceito para publicação em 26/06/2010. 